\title{
Desafios da Gestão Escolar: \\ Um Estudo de Caso da Escola Pública Senador Nilo Coelho - Dormentes/PE
}

\author{
Raquel Rita Coelho' ${ }^{\text {; Eugenio Reis de Assis }}{ }^{2}$; Suzana Benedita de Macedo ${ }^{3}$
}

Resumo: A administração escolar por muito tempo foi vista apenas como gerenciamento por parte de um diretor, e os demais cumprindo as ordens do mesmo, com a implantação da gestão escolar, surge não apenas a mudança de nomes, mas a mudança de modelo administrativo e busca de melhorias para o ambiente escolar. Diante disto, percebe-se que mesmo com uma base teórica forte que defende o modelo de gestão escolar democrática, participativa, na prática o processo ainda encontra dificuldades para ser estabelecido. Desta forma, objetiva-se conhecer os desafios perante ao modelo e posturas envolvidas e desenvolvidas na gestão pública da escola em questão. Desenvolvendo uma pesquisa bibliográfica para levantamento de material acerca da temática e pesquisa de campo para contato direto com a realidade da escola estudada. Tal pesquisa caracteriza como qualitativa visando questões qualitativas do fenômeno e como exploratória e descritiva, visando maior familiaridade com a temática e descrição da mesma.

Descritores: Escola Pública; Desafios de Gestão; Gestão Escolar.

\section{Challenges of School Management: \\ A Case Study of the Public School Senator Nilo Coelho - Dormentes / PE}

\begin{abstract}
School administration has long been seen only as management by a director, and the others fulfilling the orders of the same, with the implementation of school management, arises not only the change of names, but the change of administrative model and improvement of the school environment. In view of this, it can be seen that even with a strong theoretical base that supports the model of democratic, participatory school management, in practice the process still finds difficulties to be established. The objective is to know the challenges faced by the model and postures involved and developed in the public management of the school in question. Developing a bibliographical research to collect material about the subject and field research for direct contact with the reality of the school studied. Such research characterizes as qualitative aiming at qualitative issues of the phenomenon and as exploratory and descriptive, aiming at greater familiarity with the theme and its description.
\end{abstract}

Keywords: Public School; Management Challenges; School management.

\footnotetext{
${ }^{1}$ Graduada em Administração pela Universidade Federal do Vale do São Francisco - UNIVASF.

Contato: raquelcoelhoadm@ hotmail.com

2 Bacharel em Administração pela Faculdade Latino-Americana de Educação - FLATED

${ }^{3}$ Mestranda em Ciências da Educação - Inovação Pedagógica pela Funchal Portugal / UMA.

Contato: suzana_joao@hotmail.com
} 


\section{Introdução}

No Brasil, o conceito de gestão escolar é recente. É fruto de muitas reformulações de concepções e de conceitos, a gestão escolar, por um longo período na história da educação brasileira foi vista apenas nas dimensões gerencial e tecnicista. Guiada pela concepção empirista, a escola como instrumento reprodutor da ideologia do sistema social, era dirigida por um diretor, o dono do poder. Era isso que era vivenciado no ambiente escolar e essa compreensão que se tinha era então de direção escolar e não uma concepção de gestão escolar.

A concepção de gestão escolar não se resume apenas a mudança de termologias direção/gestão, mas a mudanças de concepção. Quando se fala em gestão escolar atualmente, nos remete a pensar em gestão educacional, uma gestão escolar envolvente que associa a democracia, a participação e a atuação aos novos ambientes de trabalho e realidade pedagógica, apesar dos desafios e resistências enfrentadas pelas escolas públicas.

Ao depararmos com os modelos conservadores e tradicionais que ainda se sobrepõem no dia a dia em algumas escolas, faz-nos retroagir aos paradigmas administrativos de escola para uma reflexão mais aprofundada, bem como avançar na compreensão dos conceitos de gestão participativa, autonomia escolar e flexibilização da gestão.

A teoria de gestão educacional pode ser vista sob ponto de vista da psicologia e do âmbito social. Esta por fazer parte do "modelo de democracia" e "consciência política", é aquela que escolhe por considerar o "modelo cognitivo" e "afetivo".

O tema em questão surgiu a partir da curiosidade em compreender acerca das resistências sofridas pelos sistemas educacionais locais, em que foi selecionada uma unidade para apreciar e aplicar os possíveis questionamentos aos atores envolvidos no processo de gestão escolar.

Pretende-se então responder o seguinte problema: quais os desafios encontrados pela Gestão Escolar Participativa na Escola Pública Estadual EREMSNC? Vale ressaltar que a gestão escolar necessita de autonomia para se desenvolver, de diálogo entre o poder público, sociedade civil e comunidade escolar, de modo que se constrói a participação e a democratização. Diante do que apresenta, esse projeto pretende no seu objetivo geral conhecer os desafios perante ao modelo e às posturas envolvidas e desenvolvidas na gestão da escola pública "EREM Senador Nilo Coelho", pois entender esse processo é apreciar as ações 
cotidianas, relações e condições para que os resultados almejados sejam alcançados. Diante disso, põe-se como objetivos específicos para realização deste projeto: Identificar os principais desafios da escola em análise; descrever características da gestão da escola em questão; apreciar o modelo aplicado para alcance de resultados na escola.

Além da relevância da temática que norteará outros estudos, poderá ser apreciado por gestores, professores e todos aqueles que fazem parte do ambiente escolar, ou seja, terá grande importância para a construção físico e intelectual da sociedade por contribuir para o desenvolvimento do indivíduo; levará aos ambientes acadêmicos questionamentos e novas ideias às fontes já existentes; além de proporcionar informações através de uma experiência vivenciada e fundamentada que comprove ao questionamento aprestados. Se fazendo necessário ainda de forma a compreender a atual situação do gerenciamento escolar da EREM Senador Nilo Coelho, visando melhorias para o próprio ambiente em questão, visto que esta é uma instituição de ensino com grande importância para região na qual a mesma se encontra, já que ela atua no nível médio de ensino e na educação de jovens e adultos.

É importante frisar que a escola tem o papel de disseminar conhecimento e ofertar educação de qualidade. Sabe-se ainda que os recursos, que são escassos diante da conjuntura vivenciada, não está favorecendo o sistema público de ensino.

Para responder aos questionamentos, este estudo será desenvolvido com o método de pesquisa bibliográfica, com a leitura de livros, apostilas, artigos científicos e outros materiais como documentos, além dos questionários que serão utilizados para análise de dados. Tomará como fundamentos as contribuições dos teóricos: Libâneo (2001), Dourado (2006), Paro (2000), Luckesi (2007) entre outros.

O embasamento teórico seguirá a linha de pensamento de autores como Libâneo (2001), Dourado (2006), Paro (2000), Luckesi (2007) que explanam sobra a temática em questão, entre outros autores que serão citados no decorrer do trabalho.

\section{Gestão Escolar}

Quando se fala em gestão de qualidade pode-se levar em consideração o método PDCA (Planejar, fazer, verificar, agir) de Willian E. Deming, utilizado para otimização de processos, 
sejam de produtos ou serviços. Na Gestão Educacional não é diferente, o controle eficiente como busca de soluções e mecanismos de melhoria contínua permite a sua aplicação em seu sistema escolar.

Conforme afirma Libâneo (2001, p.53):

Quando aplicada ao sistema escolar e às escolas, a qualidade total tem como objetivo o treinamento de pessoas para serem competentes no que fazem, dentro de uma gestão eficaz de meios, com mecanismos de controle e avaliação dos resultados, visando atender a imperativos econômicos e técnicos.

Como parte do processo de gestão educacional, os membros da escola devem ser capacitados para atender pelo menos os requisitos básicos exigidos para a sua função dentro do ambiente escolar como agente para a educação de qualidade. A qualidade da educação escolar se valida no sucesso social do seu aluno que, como sujeito proativo no processo de gestão escolar favorece a democratização da gestão. Segundo Durkhein (1978, p.41-42 apud ALMEIDA, 2017), o indivíduo se faz presente no meio em que está inserido como parte de um grupo.

\begin{abstract}
A educação consiste numa socialização metódica das novas gerações. Em cada um de nós, já o vimos, pode-se dizer que existem dois seres. Um, constituído de todos os estados mentais que não se relacionam senão conosco mesmos e com os acontecimentos de nossa vida pessoal; é o que poderia chamar de SER INDIVIDUAL. O outro é um sistema de ideias, sentimentos e hábitos, que exprime em nós, não a individualidade, mas o grupo ou os grupos diferentes de que fazemos parte; tais são as crenças religiosas, as crenças ou práticas morais, as tradições nacionais ou profissionais, as opiniões coletivas de toda a espécie. Seu conjunto forma o ser social. Constituir esse ser social em cada um de nós - Tal é o fim da educação (DURKHEIN, 1978, p.41-42 apud ALMEIDA, 2017).
\end{abstract}

Nas abordagens de teóricas da educação sobre a função da educação na sociedade podemos perceber que a doutrina é baseada pela filosofia de vida. Isto é, o sistema educacional é capaz de influenciar ou manter uma relação social entre os indivíduos.

\title{
A importância da Gestão Escolar Democrática e Participativa
}

As estruturas formadas por organizações, instituições, e ambientes escolares são consideradas sistemas abertos com maior grau de participação. No contexto da administração 
escolar, o gestor é o principal agente do processo de democratização da gestão. É ele quem articula a comunidade local e promove participação de todos para aplicabilidade do método PDCA. Dourado (2006) define a gestão democrática "como instrumento de participação e autonomia, é um processo contínuo que almeja a transformação da instituição e da própria sociedade na qual está inserida”. Enquanto Paro (2000, p. 78), argumenta acerca da democracia da seguinte forma:

Se a verdadeira democracia caracteriza-se, dentre outras coisas, pela participação ativa dos cidadãos na vida pública, considerados não apenas como "titulares de direito", mas também como "criadores de novos direitos", é preciso que a educação se preocupe com dotar-lhes das capacidades culturais exigidas para exercerem essas atribuições, justificando-se, portanto a necessidade de a escola pública cuidar, de forma planejada e não apenas difusa, de uma autêntica formação do democrata. (PARO, 2000, p. 78).

Todo modelo de gestão escolar se fundamenta nas concepções da administração empresarial que usa os meios para produzir os fins. Nessa concepção, a concepção de gestão democrática precisa articular os meios aos fins. Nesse processo, o gestor escolar é o mobilizador de toda comunidade escolar. Ele é o articulador da participação de cada um, como sujeito do processo para a efetivação de sua participação como meio para alcançar o determinado fim, ou seja, uma educativa de qualidade social como resultado do trabalho da equipe escolar.

Toda concepção de gestão tem uma tendência ideológica que a norteia. A tomada de decisão na gestão democrática é constituída pelos princípios e eixos norteadores, segundo Almeida (2017):

Tabela 1 - Princípios e Eixos norteadores da Gestão democrática

\begin{tabular}{l|l}
\hline \multicolumn{1}{c|}{ PRINCÍPIOS } & \multicolumn{1}{c}{ EIXOS NORTEADORES } \\
\hline $\begin{array}{l}\text { DESCENTRALIZAÇÃO A figura do diretor de posições } \\
\text { verticais e autoritárias é substituída pelo gestor de postura } \\
\text { flexível e conciliadora. }\end{array}$ & $\begin{array}{l}\text { REPRESENTAÇÃO LIVRE DIANTE DO PODER Com o } \\
\text { conceito de gestão nasce à organização coletiva da escola e } \\
\text { o fortalecimento dos segmentos escolares. }\end{array}$ \\
\hline $\begin{array}{l}\text { PARTICIPAÇÃO A hierarquia dá lugar ao colegiado, ou } \\
\text { seja, a participação coletiva nas tomadas de decisões. }\end{array}$ & $\begin{array}{l}\text { PARTICIPAÇÃO E DECISÃO COLEGIADA E } \\
\text { DEMOCRÁTICA Aqui temos a valorização dos atores } \\
\text { escolares e sua participação no processo de tomada de } \\
\text { decisões e planejamento. }\end{array}$ \\
\hline $\begin{array}{l}\text { AUTONOMIA A escola passa a ter mais poder nas } \\
\text { tomadas de decisões e também a gerir os recursos sem } \\
\text { interferências das secretarias de educação, como também } \\
\text { podem estabelecer parcerias com instituições públicas e } \\
\text { privadas. }\end{array}$ & $\begin{array}{l}\text { ELEIÇES DE DIRIGENTES Esse aspecto torna o } \\
\text { trabalho da escola muito mais inclusivo e democrático, pois } \\
\text { favorece, desde já, o exercício da cidadania e a autonomia } \\
\text { do sujeito, o respeito a sua opinião e sua participação na } \\
\text { construção coletiva da escola. }\end{array}$ \\
\hline
\end{tabular}

Fonte: Almeida (2017) 
Na conquista da educação pública, a Constituição Federal do Brasil de 1988 já assegurou na legislação os princípios da gestão democrática, conforme trazido por Almeida (2017):

Art. 206. O ensino será ministrado com base nos seguintes princípios:

VI - Gestão democrática do ensino público, na forma da lei;

Na LDB (em 1996) a GD aparece mais explicitamente nos artigos 3, 14 e 15:

\begin{abstract}
Art. $3^{\circ}$ - $\mathrm{O}$ ensino será ministrado com base nos seguintes princípios:
VIII - gestão democrática do ensino público, na forma desta Lei e da legislação dos Sistemas de ensino;

Art. 14- Os sistemas de ensino definirão as normas da gestão democrática do ensino público na educação básica, de acordo com as suas peculiaridades e conforme os seguintes princípios:

I - Participação dos profissionais da educação na elaboração do projeto pedagógico da escola;

II - Participação das comunidades escolar e local em conselhos escolares ou equivalentes.

Art. 15. - Os sistemas de ensino assegurarão às unidades escolares públicas de educação básica que os integram progressivos graus de autonomia pedagógica e administrativa e de gestão financeira, observadas as normas gerais de direito financeiro público.
\end{abstract}

\title{
O Papel do Gestor Escolar
}

$\mathrm{Na}$ ideologia em que a escola não só redime e nem a penas reproduz a sociedade, mas, que pode transformá-la pela ação interativa do sujeito com a sociedade, o gestor escolar tem um papel de liderança autêntica, liderança essa que não diz respeito apenas a ter poder e mandar da forma que desejar no ambiente escolar. O gestor é então o responsável na arquitetura do envolvimento entre os sujeitos com o sentimento de pertença e com o meio para alcançar os determinados fins.

Quando uma gestão contribui para a participação e cooperação dos membros de uma estrutura escolar, ou seja, todos os envolvidos no sistema de ensino recebem suporte, qualificação, reconhecimento, e consequentemente, a escola obterá sucesso na execução das metas em consonância com os objetivos de seus colaboradores/parcerias.

De acordo com Luckesi (2007, p. 15) “uma escola é o que são os seus gestores, os seus educadores, os pais dos estudantes, os estudantes e a comunidade; 'a cara da escola' decorre da 
ação conjunta de todos esses elementos”. Isto é, a escola depende do engajamento de todos os seus atores para conseguir desenvolver suas atividades com excelência.

No processo de atuação que visa o profissionalismo e o desenvolvimento dos envolvidos no âmbito escolar, Castiglioni (2007 apud FELGAR, MORAES. 2013) traz os seguintes requisitos:

a) formação dos gestores - observa-se uma formação inicial precária, onde não se tem um foco na função diretiva; quanto à formação continuada pode ser considerada pouco significativa ora por ser muito teórica ora por ser muito técnica;

b) inovação tecnológica - vai muito além de equipamentos tecnológicos, pois engloba, também, serviços, ideias e formas de realização e manutenção da instituição, como maneira de garantir a qualidade do processo educacional;

c) planejamento, monitoramento e a avaliação - muitas escolas ainda realizam seus planejamentos somente com o objetivos de cumprir normas legais; não realizam o acompanhamento dos indicadores e resultados e a avaliação ainda está sendo utilizada como forma de pontuação.

Quanto à inovação tecnológica, a sua contribuição no que se refere à implantação de sistemas gerenciais que auxiliam no planejamento, não conseguem substituir totalmente o papel do profissional que conduz o andamento dos processos da escola ou instituição. No entanto, é uma ferramenta indispensável para a qualidade da gestão escolar. São os dados que mostram a realidade em que se encontra a escola. Ao gestor cabe a habilidade de pensar os recursos técnicos, financeiros e pedagógicos para alcançar os fins determinados.

Vale dizer que as inovações tecnológicas por si só não transformarão a gestão escolar. As tecnologias são ferramentas que auxiliam e muito o gestor a qualificar sua gestão, visto que, ainda acontece gestão escolar sem o acesso às inovações tecnologias, e com a utilização da mesma, consegue-se obter melhorias diante do processo da gestão escolar.

São situações em que os esforços são somados, apenas a gestão econômica/eficiente de recursos, fazendo uso apenas da criatividade, sem a presença de tecnologias, ainda assim, consegue gerar bons resultados. Os recursos tecnológicos influenciam, mas, não determinam a qualidade da gestão escolar e nem o papel do gestor. 


\title{
Alguns desafios já identificados na Gestão Escolar Pública
}

O modelo de gestão como conjunto, flexibilidade, autonomia, planejamento coletivo, formação de professores e reflexão do processo apresenta uma série de conflitos de identidade quando confrontam as visões da administração escolar, principalmente quando ela segue a perspectiva de autoridade, burocrática, centralizada e continuam presas à dimensão gerencial. De acordo com Lück (2007, p. 20):

\begin{abstract}
A escola é uma organização social constituída pela sociedade para cultivar e transmitir valores sociais elevados e contribuir para a formação de seus alunos, mediante experiências de aprendizagem e ambiente educacional condizentes com os fundamentos, princípios e objetivos da educação. O seu ambiente é considerado de vital importância para o desenvolvimento de aprendizagens significativas que possibilitem aos alunos conhecerem o mundo e conhecerem-se no mundo, como condição para o desenvolvimento de sua capacidade de atuação cidadã.
\end{abstract}

Para isso, uma boa gestão deve conciliar as dimensões pedagógicas, administrativas, política e sócio cultural. A promoção do trabalho coletivo, decisões coletivas, consultas aos grupos, ou seja, práticas gestoras colaborativas na busca de uma educação de qualidade.

Luck (2009) coloca que o diretor é aquele que deve garantir o funcionamento pleno da escola como uma organização social, só que na prática não há necessariamente o passo a passo de como garantir esse funcionamento. Inclusive Fillipin (2013) fala que as ações a serem desenvolvidas pela gestão, nem sempre são bem explicadas em como desenvolvê-las, o que reforça essa ideia da dificuldade em como atuar qualitativamente. Até mesmo por conta de cada ambiente ser único e particular, a gestão de cada escola será de igual maneira, visando atender suas demandas. Isso então é visto como uma possibilidade de problema enfrentado na gestão escolar, visto que nem todo gestor tem preparo verdadeiro para gerir a escola em suas necessidades.

Fillipin (2013) corrobora com a ideia de Luck quando ela afirma que o gestor nem sempre se lembra que deve compartilhar as tarefas com sua equipe, ou seja, não podendo pensar ser dono da escola, e mandar em tudo sozinho, centralizando o poder nele, mas sim dividindo o poder da gestão, de forma que consiga trabalhar e enfatizar os aspectos que são requeridos por uma gestão de qualidade.

A autora Luck (2009) ainda vai dizer que: 
Novos desafios e exigências são apresentados à escola, que recebe o estatuto legal de formar cidadãos com capacidade de não só enfrentar esses desafios, mas também de superá-los. Como consequência, para trabalhar em educação, de modo a atender essas demandas, torna-se imprescindível que se conheça a realidade e que se tenha as competências necessárias para realizar nos contextos educacionais os ajustes e mudanças de acordo com as necessidades e demandas emergentes no contexto da realidade externa e no interior da escola (LUCK, 2009, p. 16).

De acordo com a mesma é possível perceber que a tarefa de desenvolver uma gestão escolar de qualidade não é fácil, requer muito esforço e dedicação para alcançar os objetivos da mesma. A necessidade não é apenas em buscar fazer um trabalho de qualidade, mas buscar atender com qualidade a comunidade escolar como um todo, compreendendo a realidade dos agentes envolvidos e desenvolver as competências necessárias para realizar o trabalho.

Santos e Fonseca (2008) afirmam que a gestão participativa pode ser considerada a melhor forma de ter bons resultados no ambiente escolar. Para as autoras esse formato de gestão vai colocar os agentes envolvidos no processo educacional em situação de contato com os problemas, mas também na busca pela solução, visto que como eles que estão diariamente em contato com o meio, e conhecem toda a rotina do corpo, podem contribuir. Entende-se então que a partir da participação dos funcionários na resolução das situações problema, eles podem expor ideias inteligentes e criativas para auxiliar nas resoluções, assim como diretores e gestores, e desta forma eles agregam diferentes valores e melhoram os resultados.

O difícil diante da visão de Santos e Fonseca (2008) é que a necessidade e a busca de melhor participação de todo o corpo escolar nem sempre aconteça como deveria, muitas vezes há mais reclamações do que busca por soluções, assim como muitos optam por se calar e ainda há os vestígios do modelo antigo de gestão, que não permitia essa participação, e que gera resistência de colocação de muitos profissionais.

Sendo assim possível identificar que apesar de ser uma ótima forma de administrar o ambiente escolar, ainda há muito o que se trabalhar e desenvolver diante desta atuação, pois apesar de já estar sendo desenvolvida, teoricamente, a prática ocorre com particularidades, que necessitam de olhares diferenciados. 


\section{Breve Descrição do Município de Dormentes/PE}

A emancipação ocorreu pela lei estadual $n^{0}$ 10625, de 01-1991, desmembrado de Petrolina. A instalação do município deu-se em $1^{\circ}$ de janeiro de 1993. Sua área territorial sofreu acréscimo com a criação dos seguintes distritos: Lagoas, Lagoa de Fora, Monte Orebe, Caatinga Grande e Vila Nova.

Conforme dados do (IBGE, 2010) são 16.917 pessoas Residentes, área Urbana composta por 6.004 pessoas e 10.913 pessoas residentes em área rural. Sua área territorial compreende 1.537,64 $\mathrm{km}^{2}$ de extensão. Bioma caracterizado pela Caatinga, localizada na Mesorregião do São Francisco, microrregião de Petrolina, a uma distante de 885 km da capital pernambucana.

Quanto às unidades de ensino, o município conta com a rede municipal que é formada por 19 escolas (interior e sede) - de acordo com as informações fornecidas pela Secretaria de Educação do município (2018), nessa rede municipal estão matriculados 3.099 (três mil e noventa e nove) alunos. Uma unidade da rede privada - possui 94 alunos em Educação Infantil e Ensino Fundamental I. Além dessas, o município conta com a contribuição da Escola de Referência em Ensino Média Senador Nilo Coelho.

\section{Breve histórico da Escola de Referência em Ensino Médio Senador Nilo Coelho}

A Escola de Referência em Ensino Médio Senador Nilo Coelho situa-se a Rua Jacob Vieira de Carvalho, Sn, Loteamento Novo Dormentes, Município de Dormentes -PE.

Este nome, Senador Nilo coelho, foi dado à Escola em homenagem ao político da região de Petrolina que teve uma grande participação no desenvolvimento da Região. Nilo Coelho foi Governador de Pernambuco, nomeado pelo Presidente da República, Humberto de Alencar Castelo Branco, governou entre 1967/1971; Senador de 1979 a 1983; duas vezes Deputado Estadual e três vezes Federal; foi ainda secretário da Fazenda de Pernambuco e de 1952 a 1954 e Presidente do Senador federal de 1983 a 1985.

Fundada em 1986, como Escola Municipal de Petrolina, a Escola Senador Nilo Coelho oferecia ensino fundamental e médio, inclusive o curso de Habilitação Básica em Agropecuária. 
O curso de Habilitação Básica em Agropecuária foi implantado em fevereiro de 1986 com base no parecer $n^{\circ} 3.474 / 75$ co Conselho Federal de Educação, autorizado pela portaria $n^{\circ} 0020$ de 25 de fevereiro de 1987, D.O. 26 de Fevereiro de 1987.

Em 08 de abril de 1994, devido à emancipação política da cidade de Dormentes, ocorrida no ano anterior, o município passa a responsabilidade do ensino médio para o Estado, criando a Escola Municipal Mauricio José Rolim Cavalcanti, a qual passa a ser dona do Prédio escolar, funcionando assim, duas escolas em um único local até 2001, ano em que a Escola Senador Nilo Coelho Passa a operar em salões comerciais alugados espalhados no centro da cidade, comprometendo com a qualidade da educação.

Após lutas e reivindicações da comunidade, educadores e estudantes junto ao governo do Estado, em 2010, a escola Senador Nilo Coelho conquistou seu prédio próprio e passou a oferecer Ensino Médio em jornada semi-integral e Educação de Jovens Adultos Médio, tornando-se Escola de Referência em Ensino Médio Senador Nilo Coelho - EREMSNC, conforme decreto $\mathrm{n}^{\mathrm{o}} 34.608$, de 12 de fevereiro de 2010 .

Conforme dados do Portal SIEPE, 2018, a escola atende os Cursos EJACAMPOA, EJACAMPOE, EMEJA e EMI totalizando uma demanda de 537 (quinhentos e trinta e sete) alunos.

Hoje, a escola Senador Nilo Coelho apresenta constante evolução quanto ao seu papel como construtora de conhecimentos significativos para influenciar a sociedade e o mundo em todos seus aspectos positivos.

\section{Metodologia}

Os dados coletados serão usados de acordo com a realidade da pesquisa apresentada. As informações prestadas serão submetidas sem riscos e exposição desnecessária dos atores respondentes.

São propostos dois critérios· básicos a serem utilizados numa pesquisa, quanto aos fins e quanto aos meios. Quanto aos fins, a pesquisa terá como critério de classificação um estudo exploratório e descritivo. Segundo definição de Gil (2002, p. 41), ele é exploratório porque proporciona "maior familiaridade com o problema, com vistas a torná-lo mais explícito ou a 
constituir hipóteses. Gil, 2007, apud (GERHARDT; SILVEIRA, 2009) diz o seguinte sobre esse tipo de pesquisa:

\begin{abstract}
Tem como objetivo proporcionar maior familiaridade com o problema, com vistas a torná-lo mais explícito ou a construir hipóteses. O objetivo principal é o aprimoramento de ideias ou a descoberta de intuições". A grande maioria dessas pesquisas envolve: (a) levantamento bibliográfico; b) entrevistas com pessoas que tiveram experiências práticas com o problema pesquisado; e (c) análise de exemplos que estimulem a compreensão. Ex: pesquisa bibliográfica e estudo de caso (GIL, 2007, apud GERHARDT; SILVEIRA, 2009).
\end{abstract}

Será descritiva porque sua característica "primordial é a descrição das características de determinada população ou fenômeno ou, então, o estabelecimento de relações entre variáveis" (p. 42). Triviños, (1987, apud GERHARDT; SILVEIRA, 2009) afirma ainda que, "esse tipo de estudo pretende descrever os fatos e fenômenos de determinada realidade. Ex: estudos de caso, análise documental, pesquisa ex-post-facto”.

A abordagem do método é o qualitativo pelos recursos da pesquisa pretendidos, e como afirma Rudio (1999, apud GERHARDT; SILVEIRA, 2009) que a pesquisa científica se distingue de qualquer outra modalidade de pesquisa pelo método, pelas técnicas, por estar voltada para a realidade empírica, e pela forma de comunicar o conhecimento obtido.

Gil (2002, p. 43) define que, "para analisar os fatos do ponto de vista empírico, para confrontar a visão teórica com os dados da realidade, torna-se necessário traçar um modelo conceitual e operativo da pesquisa". Nessa ocasião, serão consideradas ideias de teórico como Libâneo (2001), Dourado (2006), Paro (2000), Luckesi (2007) entre outros.

Quanto aos meios de investigação serão utilizadas para a coleta: a pesquisa bibliográfica, a documental e o estudo de caso. “A principal vantagem da pesquisa bibliográfica reside no fato de permitir ao investigador a cobertura de uma gama de fenômenos muito mais ampla do que aquela que poderia pesquisar diretamente" (p. 45). Serão usados materiais como livros, artigos e publicações, assim como documentos de trabalho e relatórios pertinentes a pesquisa.

Tendo em vista a pesquisa documental, serão utilizados documentos e gráficos existentes sobre histórico e atuação da escola. De acordo com as definições de Fonseca (2002):

A pesquisa documental trilha os mesmos caminhos da pesquisa bibliográfica, não sendo fácil por vezes distingui-las. A pesquisa bibliográfica utiliza fontes constituídas 
por material já elaborado, constituído basicamente por livros e artigos científicos localizados em bibliotecas. A pesquisa documental recorre a fontes mais diversificadas e dispersas, sem tratamento analítico, tais como: tabelas estatísticas, jornais, revistas, relatórios, documentos oficiais, cartas, filmes, fotografias, pinturas, tapeçarias, relatórios de empresas, vídeos de programas de televisão, etc. (FONSECA, 2002, p. 32).

Segundo Vergara (1998, p. 47) conceituado como circunscrito a uma ou poucas unidades, entendidas essas como uma pessoa, uma família, um produto, uma empresa, um órgão público, uma comunidade ou mesmo um país. Tem caráter de profundidade e detalhamento. No caso em estudo, será analisado uma escola da rede pública estadual em Dormentes/PE. A escolha desse procedimento seguirá as etapas conforme definição:

Torna-se possível definir um conjunto de etapas que podem ser seguidas na maioria das pesquisas definidas como estudos de caso: formulação do problema; definição da unidade-caso; determinação do número de casos; elaboração do protocolo; coleta de dados; avaliação e análise dos dados; e preparação do relatório. Robert K. Yin (2001) e Robert E. Stake (2000) Apud (GIL, 2002, p. 137).

Serão constituídas perguntas abertas, sendo elas descritivas e comportamentais que servirão para avaliação do tipo de gestão utilizado pela escola para obtenção de indicadores que contemplam a atuação da escola nos dias atuais. Segundo Gil (2002, p. 137), a formulação do problema geralmente decorre de um longo processo de reflexão e de imersão em fontes bibliográficas adequadas. Nesse caso pretende-se fazer uso de questionários com o gestor e colaboradores da escola em estudo.

Os dados serão organizados de acordo com a participação dos atores pesquisados conforme define Kerlinger (1980, p. 353 apud ZANELLA, 2012, p. 123) como “a categorização, ordenação, manipulação e sumarização de dados" e que segundo o autor, tem por objetivo reduzir grandes quantidades de dados brutos a uma forma interpretável e mensurável.

A análise de conteúdo será adotada pelo fato de ser uma pesquisa de natureza qualitativa com questionários compostos por perguntas abertas e fechadas para busca de significado dos dados coletados. Após essa fase, será feita a escolha e a organização do material. Em seguida, analisado e submetido a um estudo aprofundado orientado pela pergunta de pesquisa. Após os resultados, a correlação do conteúdo do material tomará como base as teorias utilizadas. 
Tabela 2 - Questões abordadas nas entrevistas

\section{QUESTÕES ABORDADAS DE ACORDO COM A ATUAÇÃO DO ENTREVISTADO}

\begin{tabular}{|c|c|c|c|}
\hline ENT & ENTREVISTA 2 & ENTREVISTA 3 & ENTREVISTA 4 \\
\hline $\begin{array}{l}\text { 2. Como se } \\
\text { estabelece uma } \\
\text { gestão participativa } \\
\text { na escola pública? } \\
\text { 3. Quais condições a } \\
\text { escola pública precisa } \\
\text { oferecer para que o } \\
\text { gestor desempenhe } \\
\text { bem o seu papel? } \\
\text { 4. Quais os principais } \\
\text { desafios que a escola } \\
\text { pública enfrenta para } \\
\text { desenvolver uma } \\
\text { gestão participativa } \\
\text { eficiente e eficaz? }\end{array}$ & $\begin{array}{l}\text { 1. Qual o contributo } \\
\text { do Coordenador } \\
\text { Escolar para o } \\
\text { desenvolvimento } \\
\text { coerente da gestão } \\
\text { participativa? } \\
\text { 2. Qual a relação dos } \\
\text { membros da escola } \\
\text { para uma gestão } \\
\text { pública participativa? } \\
\text { 3. Qual a função do } \\
\text { Coordenador Escolar } \\
\text { de uma escola } \\
\text { pública? } \\
\text { 4. Quais as principais } \\
\text { contribuições nos } \\
\text { processos de } \\
\text { interação para uma } \\
\text { gestão de qualidade? }\end{array}$ & 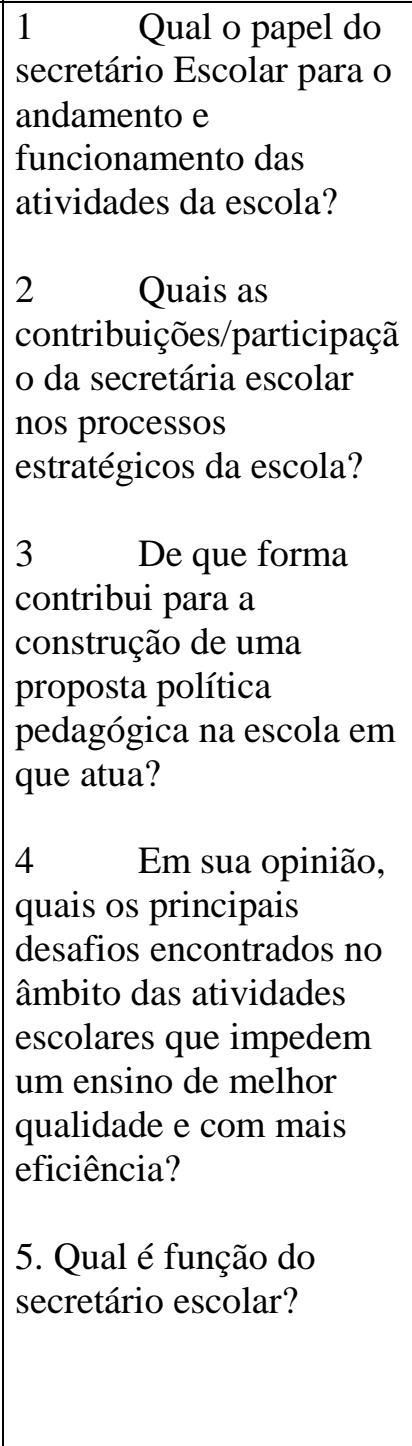 & $\begin{array}{l}\text { 1. Qual o contributo do } \\
\text { Assistente de Gestão para } \\
\text { o desenvolvimento } \\
\text { coerente da gestão } \\
\text { participativa? } \\
2 \text { Qual a relação dos } \\
\text { membros da escola para } \\
\text { uma gestão pública } \\
\text { participativa? } \\
3 \text { Qual a função do } \\
\text { Assistente na Gestão de } \\
\text { uma escola pública? } \\
\text { 4. Quais as } \\
\text { contribuições/participaçã } \\
\text { o nos processos } \\
\text { estratégicos de um ensino } \\
\text { de qualidade na escola } \\
\text { pública? }\end{array}$ \\
\hline
\end{tabular}

Fonte: Elaborado pela autora 
Tabela 3 - Entrevistas aplicadas em campo (Atores respondentes)

\begin{tabular}{l|l}
\hline QUESTIONARIOS & ENTREVISTADOS \\
\hline QUESTIONARIO 01 & DIRETOR \\
\hline QUESTIONARIO 02 & COORDENADOR \\
\hline QUESTIONARIO 03 & SECRETÁRIO ESCOLAR \\
\hline QUESTIONARIO 04 & ASSISTENTE DE GESTÃO \\
\hline
\end{tabular}

Fonte: Elaborado pela autora

\section{Resultados e Discussão}

A direção da escola quando questionada acerca do modelo de gestão escolar e da atuação do gestor escolar afirmou a função articuladora do gestor diante de sua prática, visando condução e deliberação das funções dos membros participantes do corpo escolar, devendo ainda convidar toda a comunidade escolar para participar do processo de administração e tomada de decisão para o ambiente escolar.

Entretanto é possível visualizar uma dificuldade de explanar acerca do estabelecimento da gestão escolar, compreendendo a mesma apenas pela escola de gestores da escola, e das posições e conselhos formados diante do espaço escolar. O que pode demonstrar um impacto de dificuldade no desenvolvimento do processo de gestão, por não ter o estabelecimento e funcionamento da mesma bem esclarecidos por parte do corpo.

Gerir com qualidade foi um ponto essencial levantado diante do processo de gestão escolar, em que deve-se buscar a qualidade na atuação e no processo de tomada de decisões, como Lück (2009) fala, que a gestão escolar deve passar por um processo conjunto da busca de soluções, que sejam unidas de forma inteligente e criativa, mas melhorar a qualidade da gestão escolar. Observando-se então a necessidade de ter estas participações para assim ter qualidade na gestão e bons resultados existirem.

É evidente a necessidade da escola se renovar diante das adversidades e desafios que vão surgindo no decorrer da prática, e isto é afirmado pelos diversos setores do ambiente escolar, em que a mesma deva criar mecanismos para atuar diante as dificuldades, respondendo às prioridades e dificuldades do ambiente.

A boa relação entre os participantes do corpo escolar é essencial para que o processo de gestão se desenvolva com qualidade, entretanto é compreensível, como afirma Campos e Godoy 
(2013) que relacionar-se com o outro é um processo difícil. As pessoas são diferentes, possuem pensamentos e características diferentes, e compreender e aceitar o outro nem sempre é fácil, as opiniões divergem, mas o importante no final é ter consciência de buscar o melhor e tentar um consenso pelo mesmo.

A coordenação juntamente com a direção escolar vai trabalhar para contribuir para o desenvolvimento da educação, que será refletido no desenvolvimento em sala de aula, e a relação mais encarada como necessária para esses profissionais foi a parceria que novamente retorna ao relacionamento com o outro. Relacionamento esse em conjunto e união, visando o melhor para o ambiente educacional. Campos e Godoy (2013) afirmam que o processo de interação, para ocorrência da parceria surge da aceitação do outro, em que o respeito e o acolhimento do outro e para com o outro irá facilitar a convivência entre eles.

O trabalho articulado, formador e transformador é essencial para o processo de gestão escolar, pois é a partir da união dos diferentes pensamentos e visões, que se pensam em soluções eficazes para as situações-problema enfrentadas pelo meio. Esse processo, inclui o que afirma Lück (2009) em que é necessário ouvir as diferentes partes do campo escolar, para assim ter ideias de todos os espaços e vivências, o professor que vivencia o contato diretamente e diariamente com os alunos, a direção e coordenação que encaram a vivência e os percalços administrativos, os alunos que são os sujeitos do ambiente, e a comunidade escolar como um todo que são peças fundamentais deste processo. Fillipin (2013) também corrobora com essa ideia da união das diferentes visões, buscando um processo qualitativo e descentralizado da tomada de decisão.

Entretanto, para se articularem as diferentes opiniões acerca do que houver de ser resolvido e modificado no ambiente escolar, é necessário entrar em consenso, conseguir ter boa relação entre o corpo, entre os membros, e para isso o gestor se faz essencial, como se afirma em:

O gestor é responsável pelo sucesso ou o fracasso de relação interpessoal de qualidade, pois é o articulador do processo e o incentivador do trabalho coletivo. É necessário que o gestor esteja sempre atento ao processo comunicativo desenvolvido na escola. Visto que a comunidade escolar é composta por pessoas com personalidades distintas, a comunicação é um aspecto muito relevante (CAMPOS, GODOY, 2013, p.6). 
Os papéis vivenciados e desenvolvidos pelos diferentes membros do espaço escolar se aproximam, se complementam, mas não são iguais, eles são diferenciados em sua função específica, o diretor atua em um determinado segmento, coordenação em outro, secretaria e assistentes, assim como demais funcionários. Cada um tem uma função básica e específica, que deve ser cumprida em suas atribuições, mas todos encontram-se em contato com o ambiente escolar, e todos de igual maneira podem e devem participar da gestão escolar para que a mesma apresente melhor qualidade. É necessário, como explicitado pelos entrevistados, que esse modelo de gestão, participativa, conte com a percepção de cada sujeito atuante na mesma como uma peça de fundamental importância para o desenvolvimento da mesma. Devendo cada um atuar, cobrar e querer o melhor. Como afirma o filósofo Mário Sérgio Cortella (2016) não é fazer o melhor sendo o melhor do mundo, nem salvar o mundo com uma única ação, mas sim fazer o melhor que você puder no momento atual, enquanto não se pode fazer melhor ainda, então é dar o seu melhor enquanto não se tem meios de conseguir fazer algo melhor que o possível do momento.

Percebe-se então que ainda há muitos desafios a serem sanados, sendo objetivos a serem alcançados, como formação continuada, melhor relacionamento e participação das famílias, maior envolvimento dos componentes do corpo escolar, o desenvolvimento e a prática do trabalho em grupo, mas compreender que os gestores da EREM Senador Nilo Coelho já possuem uma ideia do processo de gestão escolar participativa, e demonstram empenho em exercê-la, já se tem uma busca de melhorias para o ambiente escolar.

\section{Considerações Finais}

Diante do exposto, é possível compreender que tanto os autores quanto os participantes da pesquisa encaram a gestão participativa escolar como um ponto positivo, que visa melhorias para todo o desenvolvimento da instituição de ensino, buscando maiores cobranças e melhores resultados.

É possível perceber também que o trabalho ele não é de via única, pelo contrário, o trabalho da escola com gestão participativa tem uma atuação que perpassa por diversos caminhos, da direção para funcionário, para alunos, para pais de alunos e estes que se inter- 
relacionam entre si, e desenvolvem, juntos, como uma equipe, um trabalho de qualidade para o ambiente educacional.

É visível que ainda há dificuldades diante da proposta de gestão participativa nas escolas, visto que contar com a participação de todos os envolvidos com a vida escolar, é contar também com a disponibilidade, boa vontade, dedicação e busca de melhorias por parte dos mesmos, e muitas vezes não é realmente o que acontece diante do quadro escolar vivenciado socialmente.

Foi encontrado ainda, como possível problemática da gestão participativa a questão referente à participação dos pais de alunos no processo de gestão, pois diante da sociedade atual vivenciada, encontram-se mudanças sociais, e a instituição de ensino fica neste meio, recebendo os respaldos destas transformações. Pais com vidas mais corridas, menos tempo para os filhos, muitas vezes até terceirizando o processo de educação da criança, do jovem e se tornando cada vez mais ausentes no ambiente de ensino. Desta forma, a fiscalização para o serviço de gestão escolar fica reduzida pela parte dos pais, o que implica e comprova a posição dos autores diante das dificuldades encontradas.

Percebe-se ainda uma escassez de escritos acerca das dificuldades da atuação da gestão escolar participativa, visualizando não apenas a teoria da implantação, mas os atributos e atribuições da prática que são dificultados no processo.

\section{Referências}

ALMEIDA, Evaneide Ferreira. Gestão da Educação Escolar. Curso Técnico em Multimeios Didáticos: Educação a distância/Gestão da Educação Escolar. - Recife: Secretaria Executiva de Educação Profissional de Pernambuco, 2017.

CAMPOS, Carmen Regina de; GODOY, Miriam Adalgisa Bedim. Relações Interpessoais: um desafio para o gestor escolar. XI Congresso Nacional de Educação - EDUCERE, II Seminário Internacional de Representações Sociais, Subjetividade e Educação - SIRSSE, IV Seminário Internacional sobre Profissionalização Docente SIPD da Pontifícia Universidade Católica do Paraná, Curtitiba, 2013.

CORTELLA, Mário Sérgio. Você está fazendo o teu possível ou o teu melhor? Blog A soma de todos afetos. Agosto, $2016 . \quad$ Recuperado em: 
https://www.asomadetodosafetos.com/2016/08/voce-esta-fazendo-o-teu-possivel-ou-o-teumelhor-por-mario-sergio-cortella.html

DOURADO, Luiz F. A escolha dos dirigentes escolares: políticas e gestão da educação no Brasil. In: FERREIRA, Naura S. Carapeto (Org.). Gestão democrática da educação: atuais tendências, novos desafios. $5^{\text {a }}$ ed. São Paulo: Cortez, 2006.

Escola de Referência em Ensino Médio Senador Nilo Coelho - EREMSNC. Disponível em: http://escolasenadornilocoelho.blogspot.com.br/. Acesso em 14/10/2017.

FELGAR, Júlia Antonietta Simões. MORAES, Nanci de Campos. A Importância da Gestão Escolar Democrática. VI Congresso de Iniciação Científica do Centro Universitário de Araras "Dr. Edmundo Ulson" - UNAR. 2013

FILLIPIN, Tagiane Michele. Gestão Escolar Democrática: dificuldades, especificidades e possibilidades a partir da revista nova escola. Monografia de Conclusão de Curso, do Curso de Pós-Graduação à distância da Especialização Lato Sensuem Gestão Educacional da Universidade Federal de Santa Maria. Três Passos - RS, 2013.

FONSECA, J. J. S. Metodologia da pesquisa científica. Fortaleza: UEC, 2002. Apostila.

GERHARDT, Tatiana Engel; SILVEIRA, Denise Tolfo. Métodos de pesquisa. Universidade Aberta do Brasil - UAB/UFRGS e pelo Curso de Graduação Tecnológica - Planejamento e Gestão para o Desenvolvimento Rural da SEAD/UFRGS. - Porto Alegre: Editora da UFRGS, 2009.

GIL, Antônio Carlos. Como elaborar Projetos de Pesquisa. $4^{\text {a }}$ Ed. - São Paulo. Atlas, 2002.

LIBÂNEO, José Carlos. Organização e Gestão da Escola. Goiânia: Alternativa, 2001.

LÜCK, Heloísa. Dimensões da gestão escolar e suas competências. Curitiba: Editora Positivo, 2009.

LUCKESI, Carlos Cipriano. Gestão democrática da escola, ética e sala de aula. $\mathrm{ABC}$ Educatio, n. 64. São Paulo: Criarp, 2007.

PARO, Vitor Henrique. Administração escolar: introdução crítica. São Paulo: Autores Associados, 2000.

SANTOS, Josiana Rodrigues dos; FONSECA, Lydiene Moreira. A gestão participativa no cotidiano escolar. AFIRSE, 2008. Recuperado em: http://www.afirse.com/archives/cd11/GT\%2008\%20-

\%20POL $\%$ C3\%8DTICAS\%20E\%20PR\%C3\%81TICAS\%20DE\%20GEST\%C3\%830,\%20F

INANCIAMENTO\%20DA\%20EDUCA\%C3\%87\%C3\%83/808AGE 1.PDF 
SILVA. Renato André Pedrosa da. Gestão Educacional e seus Desafios na Escola Pública. Brasília 2011.

VERGARA, Sylvia Constant. Projetos e Relatórios de Pesquisa em Administração. $2^{\text {a }}$ Ed. São Paulo. Atlas S.A, 1998.

ZANELLA, Liane Carly Hermes. Metodologia de estudo e de pesquisa em administração. 2. ed. reimp. - Florianópolis: Departamento de Ciências da Administração / UFSC, 2012. pág. $105-160$

\section{Como citar este artigo (Formato ABNT):}

COELHO, Raquel Rita; ASSIS, Eugenio Reis de; MACEDO, Suzana Benedita de. Desafios da Gestão Escolar: Um Estudo de Caso da Escola Pública Senador Nilo Coelho - Dormentes/PE. Id on Line Rev.Mult. Psic., 2018, vol.12, n.42, p. 436-455. ISSN: 1981-1179.

Recebido: 17/09/2018;

Aceito: 28/09/2018 